Esta sección esta abierta para todos los lectores de la Revista, a la que pueden enviar sus preguntas, comentarios o críticas a los artículos que hayan sido publicados en los últimos números, teniendo en cuenta la posibilidad de que los autores aludidos puedan responder. Podrá aceptarse la comunicación de investigaciones preliminares, o de intervenciones en brotes que no hayan sido publicados ni sometidos a publicación en otra revista; así como, algunos comentarios sobre problemas de salud pública, ética y educación médica. La extensión máxima aceptable es de 1000 palabras, con un máximo de seis referencias bibliográficas (incluyendo la referencia del artículo que la motivó, cuando sea el caso) y una tabla o figura. Esta puede ser enviada a revmedex@ins.gob.pe.

\section{NIVELES DE CÉLULAS CD4 EN PACIENTES HOSPITALIZADOS CON DIAGNÓSTICO DE DENGUE EN EL HOSPITAL DE APOYO DE IQUITOS "CÉSAR GARAYAR GARCÍA"}

\section{[LEVELS OF CD4 CELL COUNTS IN HOSPITALIZED PATIENTS WITH DIAGNOSIS OF DENGUE IN HOSPITAL “CÉSAR GARAYAR GARCÍA", IQUITOS]}

Moisés Sihuincha Maldonado ${ }^{1, a}$, Víctor Fiestas Solórzano ${ }^{2, a}$, Salomón Durand Velazco ${ }^{3, a}$, María García M. ${ }^{2, b}$ Milady Gatti ${ }^{4, c}$

Señor Editor. En diciembre de 2010 se inició en Loreto una epidemia de dengue con circulación del serotipo DENV-2 genotipo Americano/Asiático ${ }^{(1)}$ cuya transmisión se concentró en la ciudad de lquitos, siendo una de las características de esta epidemia el alto porcentaje de hospitalización de los pacientes por probable dengue con signos de alarma o dengue grave, según la última clasificación de la OMS (2). Una de las características de esta epidemia es la frecuente aparición de complicaciones infecciosas en la etapa crítica y convalecencia como: infecciones de vías respiratorias, infecciones de vías urinarias e infecciones gastrointestinales.

Se hizo una evaluación de inmunidad celular a través del conteo de células CD4, de los pacientes hospitalizados con diagnóstico de dengue en el mes de enero de 2011, que se encontraban en los primeros cinco días de enfermedad. El diagnóstico de dengue fue confirmado por ELISA Antígeno NS1, ELISA IgM y RT-PCR en tiempo real

\footnotetext{
Hospital de Apoyo de Iquitos.

2 Centro de Investigación de Enfermedades Tropicales "Maxime Kuczinsky", Instituto Nacional de Salud.

3 Centro de Investigación de Enfermedades Tropicales de la Marina de los EEUU (NAMRU-6), Perú.

4 Laboratorio Referencial de DIRESA Loreto.

a Médico Infectólogo; Tecnólogo médico; Bióloga.

Recibido: 23-02-11 Aprobado: 09-03-11
}

realizado en el Centro de Investigaciones de Enfermedades Tropicales "Maxime Kuczinsky" del Instituto Nacional de Salud en Iquitos; el conteo de células CD4 fue realizado en el Laboratorio Referencial de la DIRESA Loreto.

En 34 pacientes hospitalizados con diagnóstico de dengue con signos de alarma y dengue grave, se encontró que el promedio de conteo de células CD4 fue 489 células $/ \mathrm{mm}^{3}$, la mediana fue 461 células $/ \mathrm{mm}^{3}$ y el rango de valores varió entre 190-1317 células $/ \mathrm{mm}^{3}$; sin embargo, $20 / 34(58,8 \%)$ tenían un conteo de células CD4 menor a 500 células $/ \mathrm{mm}^{3}$ y $3 / 25(8,8 \%)$ tenían un conteo de células CD4 menor a 200 células $/ \mathrm{mm}^{3}$, lo cual indica que durante la infección por virus dengue se puede producir una depresión transitoria importante del sistema inmune celular.

En esta serie 12/34 (35,3\%) eran menores de 15 años y 18/34 (53\%) eran mujeres. Estas proporciones fueron similares en aquellos con conteo de células CD4 menor a 500 células/mm 3 : $7 / 20(35 \%)$ eran menores de 15 años y $11 / 20(55 \%)$ eran mujeres. En los pacientes con conteo de células CD4 menor a 500 células $/ \mathrm{mm}^{3}$ se determinó mediante RT-PCR en tiempo real, DENV-2 en $12 / 20$ (60\%), DENV-4 en $2 / 20(10 \%)$ y DENV-1 en $1 / 20(5 \%)$; sin embargo, en los tres pacientes con conteo de células CD4 menor a 200 células $/ \mathrm{mm}^{3}$ se encontró DENV-2.

Este es un primer reporte en el Perú que muestra una disminución de la inmunidad celular transitoria en los pacientes con infección por virus dengue que incluso puede llegar a inmunosupresión severa, el cual podría estar relacionado con complicaciones de enfermedades infecciosas observadas en la convalecencia, quedando como posibilidad que algunos pacientes podrían estar expuestos a infecciones oportunistas, de manera similar a los pacientes con SIDA, como hiperinfección por Strongyloides stercoralis dada su alta prevalencia en la Amazonía peruana. Sin embargo, se requerirán más estudios que permitan corroborar esta afirmación.

Se ha reportado que los flavivirus con expresión de proteína NS5 disminuyen la expresión genética del CD4 y producen una respuesta alterada de las citoquinas, lo cual podría estar relacionada con la gravedad de las 
infecciones por virus dengue ${ }^{(3-4)}$. Es necesario realizar otros estudios que permitan evaluar otros aspectos que influyen en la inmunidad de los pacientes con dengue.

\section{Conflictos de Interés}

Los autores declaran no tener conflictos de interés en la publicación del presente artículo.

\section{REFERENCIAS BIBLIOGRÁFICAS}

1. Mamani E, Alvarez C, García M, Figueroa D, Gatty M Circulación de un nuevo linaje del virus dengue 2 genotipo América/Asia en la Región Amazónica del Perú, 2010. Rev Peru Med Exp Salud Publica. 2011;28(1)[En prensa].

2. World Health Organization. Dengue. Guidelines for diagnosis, treatment, prevention and control. Geneva: WHO; 2009. Disponible en http://whqlibdoc.who.int/ publications/2009/9789241547871_eng.pdf. (fecha de acceso 28/02/2011.

3. Xiang J, McLinden JH, Rydze RA, Chang Q, Kaufman TM, Klinzman D, et al. Viruses within the Flaviviridae decrease CD4 expression and inhibit HIV replication in human CD4+ cells. J Immunol. 2009;183(12):7860-9.

4. Mangada MM, Rothman AL. Altered cytokine responses of dengue-specific CD4+ T cells to heterologous serotypes. J Immunol. 2005;175(4):2676-83.

Correspondencia: Moisés Sihuincha.

Hospital de Apoyo Iquitos .Cornejo Portugal 1710 IquitosLoreto.

Tel: 065-263749; 965-921615; 065-261435.

Email: Sihuincha@hotmail.com

\section{IMPACTO DE LA EPIDEMIA DE DENGUE CON UN NUEVO LINAJE DEL DENV-2 GENOTIPO AMERICANO I ASIÁTICO EN LA DEMANDA DE SERVICIOS DEL HOSPITAL DE APOYO DE IQUITOS "CÉSAR GARAYAR GARCÍA"}

\section{[IMPACT OF THE DENGUE EPIDEMIC DUE TO A NEW LINEAGE OF DENV-2 AMERICAN/ ASIAN GENOTYPE IN THE HEALTH SERVICES DEMAND IN HOSPITAL "CESAR GARAYAR GARCIA", IQUITOS]}

\author{
Salomón Durand Velazco ${ }^{1, a}$, Víctor Fiestas \\ Solórzano ${ }^{2, a}$, Moisés Sihuincha Maldonado ${ }^{3, a}$, \\ Carlos Chávez Lencinas ${ }^{4, d}$, Vicente Vásquez Vela ${ }^{3, c}$, \\ Ciro Torrejón Flores ${ }^{3}$, Hugo Rodríguez Ferruchi, ${ }^{5, b}$, \\ César Cabezas Sánchez $6, a$
}

Sr Editor. Dada la importancia del dengue como enfermedad reemergente en las américas, queremos destacar el impacto de la introducción de un nuevo genotipo del DENV-2 en la región Loreto del Perú a fines del año 2010. En ese sentido, luego de la reintroducción del virus dengue en la ciudad de lquitos en la década de 1990, han ocurrido sucesivos brotes que han coincido con la emergencia de un nuevo serotipo ${ }^{(1-4)}$. En diciembre de 2010 se inició el brote epidémico de dengue asociado con el nuevo genotipo del DENV-2 . Según comunicación personal de los médicos del Hospital de Apoyo de Iquitos "César Garayar García”, ninguno de los brotes anteriores ocasionó la necesidad de incrementar el número de camas hospitalarias por la gran demanda de pacientes con signos de alarma y graves según la última clasificación de la $\mathrm{OMS}^{(5)}$, produciendo el colapso de los servicios de emergencia, hospitalización y laboratorio en los primeros días del brote.

La ciudad de lquitos conformada por los distritos de lquitos, San Juan Bautista, Punchana y Belén tiene 406340 habitantes y tiene dos hospitales públicos. El Hospital de

\footnotetext{
Centro de Investigación de Enfermedades Tropicales de la Marina de los EEUU (NAMRU-6), Perú.

2 Centro de Investigación de Enfermedades Tropicales "Maxime Kuczynski" - INS, Perú.

3 Hospital de Apoyo de Iquitos "César Garayar García” - Región Loreto, Perú.

4 Universidad Nacional Mayor de San Marcos

5 Dirección Regional de Salud Loreto, Perú.

Instituto Nacional de Salud, Lima, Perú.

Médico Infectólogo; b Médico Epidemiólogo; ' Biólogo Epidemiólogo; d Médico Residente del III año en la Especialidad de Medicina de Enfermedades Infecciosas y Tropicales.
} 